\title{
How Do CIOs Become CEOs?
}

\author{
Ron Babin, Ryerson University, Toronto, Canada \\ Ken Grant, Ryerson University, Toronto, Canada
}

\begin{abstract}
The role of information systems and technologies in any modern organization has become increasingly important. Concepts such as digital transformation and disruptive technologies have become the strategic directions for new and established companies. The role of the Chief Information Officer (CIO) has been long established. This case-based research article examines how and when a CIO becomes the CEO. This is particularly relevant as organizations embrace technology-based strategies to compete, and in many cases, to survive.
\end{abstract}

\section{KEYWORDS}

Career Opportunities, Case Studies, CEO, CIO, IT Leadership, Leadership

\section{INTRODUCTION}

Although relatively new, the position of a Chief Information Officer (the CIO) is now widely accepted as one of the key $\mathrm{C}$-suite roles ${ }^{1}$. With the continuously increasing role of technology, the demands of the position have been changing. CIOs are now responsible for more than just providing the right technology and running the IT departments; they are increasingly becoming leaders who actively participate in strategic business decisions. This transformation means that CIOs are required to develop a business-focused set of skills, but it also opens new career opportunities in other leadership roles. Specifically, an increasing number of CIOs are moving out of the technology leadership role and into Chief Operating Officer (COO) and Chief Executive Officer (CEO) positions, even though traditionally this has not been a common career path.

The goal of our research was to examine the factors which can support or prevent career progression from CIO to higher executive positions. This report is an outcome of a two- phase study sponsored by the CIO Association of Canada and MITACS-Ontario. The first phase consisted of extensive academic research and a pilot study of a group of Canadian CEOs. It identified key career characteristics and personal attributes that may help CIOs to get to CEO or COO roles.

The second phase of the study, which was also supported by executive recruiting experts at Korn/ Ferry International, expanded the initial sample and combined results to examine career progression and personal attributes of successful CEOs and COOs in three areas previously identified in Phase I: Environmental Factors (focusing on the industries and employers that the executives have worked for), Work Experience (executives' responsibilities and job experiences that shaped their know-how), and Personal Attributes (soft skill and emotional intelligence). 
The article is organized as follows. First, we examine and discuss the relevant literature regarding the role of the CIO and how CIOs may progress to become the CEO. Second, the casebased qualitative research approach is described. In the third section, the research findings from field interviews are discussed. Next, implications for IT leaders are presented with a model that describes how CIOs can develop their careers to CEO. Finally, an action plan is presented for CIOs considering their career progression.

\section{LITERATURE REVIEW}

The literature regarding the CIO role and performance is broad and we draw on selective papers that guides this research towards the CIO promotion to CEO. Similarly, as Schnatterly and Johnson (2008) have pointed out, “... research in CEO succession has been extensive-including individual, board, and firm antecedents; succession planning; and consequences...” However, the literature on CIO progression to CEO is sparse, which provides a gap for this case-based research to address.

Regarding the role of the CIO, Hutter and Riedl (2017) present a compelling model derived from a meta-analysis of 98 papers that examined the CIO role. This research concludes with a model that suggests CIOs "are increasingly called upon to be effective in multiple roles", which the authors identify as Business Thinker, Innovation Driver, Strategic Supporter, Integration Advisor, Relationship Manager and Technology Provider (p. 21, 22). Remenyi et al (2005) further point out that, "perhaps to a greater degree than other " $\mathrm{C}$ ' positions, it [the CIO position] has continued to be a role undergoing constant change and transformation", demanding different skills at different times for survival and success. Further, in an early paper examining CIO/CEO relationships, Feeney et al (1992) found that, “...the ClOs in these successful relationships may have extensive IT backgrounds, but they are accepted into the top management team and are seen to contribute beyond their functional responsibilities..." (pp. 434-435).

In a similar evaluation of the CIO role, Peppard (2010) concludes that the personal competencies of the individual, although important, are not the sole factor in determining CIO effectiveness. One interviewee states: “...CIOs need to be far more dynamic, commercially minded and communicative... [they must be] a capable business leader who understands the minutia of every aspect of the business... They have to be an influencer, not just a doer or a firefighter..." (p. 77). Peppard offers a CIO model with seven competencies: Leadership, Visionary, Strategic Thinker, Relationship Builder, Diplomat, Deliverer, Reading the Market (p. 79). In a similar tone, Hunter (2011) points out that the CIO “....takes on more of a business emphasis, [so that] experience within one industry becomes very important." (p. 47). Further, Hunter states "A CIO role involves effective leadership for change with a view to contributing to competitive advantage." (p. 48).

The CIO is often seen as the technology and business leader in digital transformation, although the role of Chief Digital Officer (CDO) is a new position that may challenge the CIO. Singh and Hess (2017) suggest that the CDO will take on the role of "orchestrating the digital transformation of a company" (p. 1), which may challenge the role of the CIO. Similarly, Heller (2016) points out that the advent of digital technologies such as cloud services, mobile technologies and big data analytics has changed the role of the CIO from supporting or enabling the business, to instead "be the business." Quoting CIOs from Marriott Hotels, Vanguard Mutual Funds and other organizations, Heller notes that "CIOs are more tightly integrated with leaders from other disciplines... interactions are much broader and richer than they were five years ago... With data at the center of the business [we have] no choice but to be the business" (pp. xiii, xiv). Describing the rise of digital transformation, Heller notes that: "When technology is the business, CIOs have a tremendous opportunity..." (p. 13). Weill and Woerner (2013) examined the role of the CIO in a Digital Economy and found that business leaders expect CIOs to do much more than "provide excellent IT services at a competitive price" and expect that CIOs need to spend "more time delivering broader business value..." (p.74). All of 
this suggests that the CIO role has evolved significantly from the technology manager of the 1980s to the digital strategist of today.

Regarding how CIOs progress to the CEO position, we identified three theoretical models with specific reference to CIO advancement. Gottschalk (2007) Supply-Side Model for CIO to CEO Evolution examines the qualifications a CIO needs to be considered for the top job, describing this as the Supply Side CIO Qualifications Model (May, 2007). Why Don't More CIO's Become CEO? Computer World draws on Peters \& Waterman's (1982) trait research, which suggests the existence of eight basic traits found in great CEO's. Finally, recent research from Dawson et al (2015) suggests that the "CIO shares similar characteristics to other C-Suite executives" such as the CEO and CFO, in terms of time in the role or "survivability" (p. 97).

\section{RESEARCH APPROACH}

Our research approach used a case-based qualitative model, guided by Yin (2009) and Eisenhardt (1989). Yin suggests that case study approach is appropriate to "...investigate a contemporary phenomenon in detail and within its real-life context, especially when the boundaries between the phenomenon and context are not clearly evident..." (p. 18). The case approach is appropriate as the role of the CIO continually changes with new digital technologies and these technologies becoming increasing important to the business strategy. As Yin points out, “...you would use the case study method because you wanted to understand a real-life phenomenon in depth..." (p. 18), in this case the phenomenon of CIO promotion to CIO. Each CIO was treated as an individual case, with the interview findings complement by a review of each interviewee's LinkedIn profile, corporate profile and CV.

In brief, from the literature review, including academic and trade literature, a model was prepared to analyze CIO career progression. A set of CEOs were identified and contacted to arrange for semistructured interviews. The interviews were transcribed and coded to identify how the comments fit with the preliminary model. The research followed Eisenhardt's case study approach, which suggests "tentative themes, concepts and possibly even relationships between variables begin to emerge" by comparing "systematically the emergent frame with evidence from each case. The central idea is that researchers constantly compare theory and data iterating toward a theory which closely fits the data" (p. 541). A thorough review of the field data, including interactions with CIOs and CEOs interviewed, allowed the research team to revise and refine (iterate) the preliminary model to develop a revised model that could provide useful advice to aspiring CEOs.

Specifically, as a first step in developing the model, from the trade literature some 50 articles or career profiles that described a CEO who had formerly been a senior IT Leader were identified, from which we found 20 to be of sufficient depth to be useful in our research. Next, we considered the three theoretical models related to CIO to CEO progression -- Rambus's (2006) CIO to COO Success Factors, Gottshalk's (2007) Supply-Side Model for CIO to CEO Evolution and May's (2007) Eight Basic Traits of the CEO. Finally, we examined two field studies that had examined aspects of CIO advancement: Egon Zehnder International's (2007): Future-State CIO: The Next Step in IT Leadership and Chatham's (2005) Getting To Be CEO via a Career in IT

By comparing these secondary field sources to the theoretical models, we developed a composite model identifying the characteristics likely to lead to CIO advancement. The preliminary model is shown in Figure $1 .^{2}$

We then tested this model through interviews with CEOs who had previously held senior IT roles. We identified and contacted some 100 potential participants who progressed from the CIO role into $\mathrm{CEO}$ or $\mathrm{COO}$ positions. Of those, 29 agreed to share their experience as well as their thoughts on $\mathrm{CIO}$ career progression drivers. Among all respondents:

- $\quad 21$ held CEO positions and 8 held COO positions;

- 14 were US-based and 15 were Canadian-based;

- Two were female. 
Figure 1. Factors likely to influence a CIO's progression to CEO

\begin{tabular}{|c|c|}
\hline Environmental Factors & $\begin{array}{l}\text { Industry } \\
\text { - Highly competitive } \\
\text { - } \text { Information intensive } \\
\text { Employer and IT } \\
\text { - CIO role reports to CEO } \\
- \text { CIO visible to the Board } \\
\text { - CIO accepted as one of the "Cs" } \\
\text { Organization is a mature user of IT }\end{array}$ \\
\hline $\begin{array}{l}\text { Executive's Work Experience } \\
\text { And Responsibilities }\end{array}$ & $\begin{array}{l}\text { - Increasing business focus } \\
\text { - } \text { Firm wide responsibilities } \\
\text { - } \text { Decision making responsibilities, ideally beyond IT } \\
\text { - Involved in customer relationships } \\
\text { - Entrepreneurial role } \\
\text { - Operating independently and provision of supervision } \\
\text { - } \quad \text { Good at the CIO basics -- technical and operations }\end{array}$ \\
\hline $\begin{array}{l}\text { Executive's Personal } \\
\text { Attributes }\end{array}$ & $\begin{array}{l}\text { - } \text { Good and specific knowledge of the business } \\
\text { - Seen as business savvy } \\
\text { - } \text { Relationship builder } \\
\text { - Executive level communication skills } \\
\text { - Strong interpersonal skills (listening, empathizing, } \\
\text { - } \text { mentor) } \\
\text { - Ghange leader } \\
\text { - } \text { Good at people and organizational development } \\
\text { - Sense of humour }\end{array}$ \\
\hline
\end{tabular}

Although most participants came from a technology background, for a few, the CIO role was their first position in Information Technology. The interviewees came from a wide variety of backgrounds and worked in different industries including, among others, software, financial services, utilities, pharmaceuticals, healthcare and education.

The qualitative interviews were semi-structured, with a mix of open and close-ended questions, ensuring consistency of the analysis while at the same time allowing for respondents' personal perspectives as suggested by Myers and Newman (2007). The participants shared with us the information about their personal career paths and their views on CIO career progression factors, as well as advice for CIOs aspiring to climb the corporate ladder.

All interviews were recorded, transcribed and analyzed through a formal coding approach. Unique codes were assigned to specific comments and examined through the use of an automated text analysis software tool. This approach allowed us to effectively analyze a large amount of data and compare respondents' comments in a consistent manner.

We examined the data to find differences between various groups of executives (such as: COOs vs. CEOs; or Canadian based vs. American-based executives; or different industry types). While the participants' backgrounds and professional paths varied, the core characteristics of the career factors they described did not. Our findings show that certain key elements can influence career progression of CIOs across various industries and career paths.

\section{RESEARCH FINDINGS}

Our research shows that CIOs are making it to the top. Although the position is relatively new (in comparison to the well-established executive roles of COO, CFO or CEO), CIOs are now gaining their seat at the executive table - not just as IT managers but as business leaders and partners in strategic discussions. While certain negative IT stereotypes still exist, successful CIOs are able to 
overcome them and advance their careers by proving themselves to be knowledgeable, engaged and business-savvy. Indeed, research from International Data Corporation (IDC) suggests that a growing number of CEOs will have spent a portion of their careers in a technology leadership role, in order to understand and lead digital transformation programs ${ }^{3}$ within the business.

Based on a comprehensive literature review, as shown earlier in Figure 1, the first phase of the research identified three key categories of factors influencing CIO career progression: Personal Attributes, Work Experience and Environmental Factors. The three categories align with the Hutter \& Riedl model of the CIO role (2017, p.9) which suggests that CIO effectiveness will be supported by personal competence (Personal Attributes), CIO hierarchical position (Work Experience) and management environment and IT infrastructure (Environmental Factors).

Data acquired from the expanded sample confirmed and validated this model. Despite our respondents' varying backgrounds and different career paths, we found that they all exhibited quite similar characteristics. The key factors among the three categories (those which were most often mentioned and discussed by the 29 participants) are presented in Figure 2. The top 14 factors presented below accounted for over $62 \%$ of all coded comments relating to career progression factors. Within that group, the top two factors - increased business focus and good at CIO basics - stood out, having received significantly more comments (both in numbers and in interviewees' perception) than the remaining factors and account for nearly a quarter of responses.

These factors paint the following picture of key CIO success and career progression determinants.

\section{Increased Business Focus}

An increased business focus was exhibited by all participants and discussed considerably more often than any other factor. All of the interviewed executives discussed this element, often stressing the importance of not only understanding the business but also being a partner who can actively participate in and bring value to business discussions. As described by one of the participants, “... successful CIOs wear their business hat first and their IT hat second..." Frydman (2007) has argued that, in terms of CEO hiring, we are witnessing "a shift toward general human capital from firmspecific managerial skills".

Being more attuned to the business needs is both necessitated and facilitated by the fact that IT touches all aspects of the business. Today, all corporate functions are supported by technology, which gives the $\mathrm{CIO}$ a unique opportunity to be involved in all parts of the organization. Being involved makes

Figure 2. Key factors influencing $\mathrm{ClO}$ career progression

\begin{tabular}{|c|c|c|c|}
\hline $\begin{array}{c}\text { WORK } \\
\text { EXPERIENCE }\end{array}$ & Increased Business Focus & Good at CIO basics & Firm-wide responsibilities \\
\begin{tabular}{|c|c|c|}
\hline $\begin{array}{c}\text { ENVIRONMENTAL } \\
\text { FACTORS }\end{array}$ & IT Governance & Organization is a mature user of IT \\
\hline
\end{tabular}
\end{tabular}

\begin{tabular}{|c|l|l|}
\hline \multirow{2}{*}{$\begin{array}{c}\text { PERSONAL } \\
\text { ATTRIBUTES }\end{array}$} & \multicolumn{1}{|c|}{ Change Leader } & \multicolumn{1}{|c|}{ Having an advisor or a mentor } \\
\cline { 2 - 3 } & \multicolumn{1}{|c|}{$\begin{array}{l}\text { PERSONAL SKILLS } \\
\text { Executive level communication skills } \\
\text { Relationship builder } \\
\text { Good at people and organizational development } \\
\text { Ability to motivate people }\end{array}$} & $\begin{array}{l}\text { BUSINESS KNOWLEDGE } \\
\text { Understanding and knowledge of the business } \\
\text { Understanding of the customer } \\
\text { Work experience }\end{array}$ \\
\hline
\end{tabular}


it much easier to align business priorities with technology capabilities, providing improved results ${ }^{4}$. This approach was further facilitated by the respondents' experience outside of IT, in functional roles.

As pointed out by interviewed executives, “...it's very important to put the business context around IT..." and to have "... an instrumental role of helping the business determine what applied technologies make sense. Not technology for technology's sake but how do we turn that technology into competitive value, market value, drive sales productivity, improve customer retention, and improve profitability..." CIOs who were able to anchor their decisions in the business context were more successful and more readily accepted by other executives.

\section{Good at ClO Basics}

Being good at CIO basics was the second most frequently discussed factor, mentioned by all interviewees. The ability to effectively deliver IT capability is a natural expectation of CIOs. However, making everything run smoothly is only part of what truly successful CIOs bring to the table.

Firstly, IT leaders have to "make the plumbing simple" and "prove that you can make things happen." However, this does not imply a strong focus on a failure-free environment or the use of the latest technology. As pointed out by the respondents, being too afraid of failure prevents many IT leaders from taking full advantage of technology (which sometimes requires taking risks). Similarly, depending on the business context, following the newest technology trends might not necessarily be the right choice for an organization. It is the ability to mitigate risks (rather than avoid them) and choose the right technology for the business that makes it possible to "execute and deliver service at the right price point and at the right level of quality". This is closely connected with an increased business focus and both factors were often discussed together by the interviewees.

As the CIO responsibilities expand beyond a strictly technical role (and become more business focused) it is also important to find the right balance between different aspects of the job. As one of the participants suggested, “...if you spend too much time on process you'll fail, if you spend too much time on technology you'll fail, if you spend too much time on people you'll fail..." It is important to get a good understanding of what mix of activities will most adequately address the requirements of a particular organization. As this changes over time, CIOs must be able to adjust their priorities accordingly.

\section{Personal Skills}

Among the personal skills discussed by the interviewees, four were mentioned most often: executive level communication skills, building relationships, being good at people development and organizational development, and the ability to motivate people.

Executive level communication skills are crucial in being able to work with the business and discuss technology-related issues in a way that is understandable to all stakeholders, regardless of their knowledge of technology. Often referred to as "C-Speak" or Executive Presence" (Goudreau, 2012), they need to talk in the language of top executives. Translating complex technical concepts into simple terms has been an important success factor for the respondents as it allowed them to bring various stakeholders to a common level of understanding and create an environment where everyone is comfortable in discussing technology. One of the executives talked about the importance of proactive communication with the business in the following way:

If I were to ask a business person to give me a blank sheet of paper saying "hey what do you need?" I don't think they would know how to fill that out. But if I went to them and said I can give you this (...) because that satisfies your needs, now I've focused their attention and got them thinking."

This example is indicative not only of the deep understanding of the business needs but also of the ability to take the complexity out of the technology discussions and turn the often-feared subject into something everyone could relate to. 
Building relationships are important to the participants because they allowed CIOs to strengthen their role internally and produced career progression opportunities. For many respondents, having good relationships was crucial in the process of building the previously described business focus and understanding the business. As mentioned earlier, IT touches all parts of the business and the relationships with the business can influence the CIOs ability to deliver results. One respondent pointed out that “often the CIO's job is about managing by influence; your peers don't have a dotted line to you and they may have the money you need to do your initiative".

Secondly, relationships and professional networks were important in the interviewees' career progression as many of the opportunities that allowed them to advance in their career were not planned but suggested or enabled by people in their network. As described by one of the executives: "Business people don't necessarily consider technologists for business roles and vice-versa without someone advocating for you internally".

Some of the respondents made a clear distinction between good working relationships and personal ones, stressing that building relationships does not mean creating close personal ties. Rather, it implies building working relationships where the $\mathrm{CIO}$ is accepted as one of the business C-level executives and where they are being trusted as both a technology expert and a business partner. As summarized by one of the interviewees, "you have to respect and professionally work together; you don't have to love each other".

Being good at people and organizational development as well as the ability to motivate people were important factors, which allowed interviewed executives to build successful teams and organizations. Many interviewees talked about creating an environment in which their teams could be successful, motivated, engaged and able to have a strong positive impact on the organization. One of the respondents described their role as being a facilitator who makes it easier for the team to do their job and to reach their objectives.

Having an engaged, knowledgeable staff allowed participants to create high performing organizations where strategic plans were executed effectively and important transformational projects were introduced successfully. One executive pointed out that “... as you move up in management it becomes much less relevant what you as an individual can deliver and much more relevant what you as a leader can... have your teams create..."

\section{Business Knowledge}

The interviewees agreed that the ability to exhibit the increased business focus is largely dependent on understanding and knowledge of the business and its industry.

Understanding how the business works provides a CIO with a context in which technology-related initiatives can be evaluated and analyzed; a project without that context "...can be successful from a technology perspective but unsuccessful for the business..." Some executives also talked about the importance of encouraging their teams to gain business knowledge. One interviewee encouraged their IT team members to find a partner on the business side and work closely with them. As the IT team learned more about the business, "they were able to come up with some very creative solutions to everyday problems of their business partners and at the end of the day we were highly impactful".

Many respondents talked about the importance of understanding the customer and being customercentric. As described by one interviewee, "you don't win clients and you don't keep clients" if you are not close to them and engaged. Being able to understand customer needs makes it possible to adequately address them and create value for the business. Simply put, “...you can't understand how to help someone unless you understand the shoes that they are in..."

Understanding of the business and of the customers cannot be superficial. As stated by one executive, “... you have to really understand the intricacies of the business not just the buzz words..." In the case of our respondents, this was enabled by work experience and having firm-wide responsibilities. Hands-on experience was often quoted as the best way to gain a true understanding of various parts of the business. Some executives gained the experience by taking different positions in various 
industries, while others diversified their responsibilities internally by engaging in M\&A activities, taking responsibility for different geographical areas, or participating in large transformational projects within their organizations.

Respondents generally agreed that successful leaders have to be able to demonstrate a range of different skills and an ability to deliver results in various environments, such as customer management, sales management, product management, marketing, financial management, risk management, governance, communications, PR or revenue growth. One interviewee compared this to filling a toolbox with a set of different tools that will come handy in the future.

\section{IT Governance and IT Maturity}

While the interviewees worked in companies with highly varying IT maturity and formal IT governance structures, they generally recognized the importance of these factors in their professional success. Both of these factors are strongly interconnected, as good IT governance structures are a sign and a product of high maturity in how an organization views their IT capabilities.

Where necessary, the respondents built or improved governance structures and increased IT maturity to levels adequate to the context of their organizations. This was important “... because if you have governance that gives you exposure to your peers, gives you exposure to the board, you know you're well positioned. If IT is integrated in with the business you're going to learn and understand the business more and really be able to perform better..."

One of the executives pointed out that "...the view of IT tends to fluctuate from strategic... to necessary evil..." Where the leadership team understood the importance of IT, the respondents were able to considerably increase the IT maturity levels and governance structures ${ }^{5}$.

\section{Change Leadership}

The respondents often talked about being change agents in their organizations, leading initiatives from major technology transformations to redefining business processes, introducing efficiencies and changing the culture of IT organizations. In each case, the executive was able to better align technology with the business needs and create an effective organization supporting strategic business goals, reducing costs and increasing business value.

A common skill that the change agents had was the ability to quickly identify problem areas, suggest ways of improvement, create an action plan, and effectively carry it out. In many cases, the organizations were facing considerable problems that often-required radical solutions (such as cutting the IT budget by $\$ 500$ million). In others, the respondents were able to identify opportunities for improvement and proactively propose ways in which the IT organization could step up (such as rationalizing technology or introducing employee engagement programs). Not all of the change efforts were revolutionary. One respondent pointed out: “...if we stand still as an organization, one of our competitors will catch up to us and surpass us... the pace of change continues to accelerate... that's why I happen to be a fan of continuous improvement..."

\section{Role of a Mentor}

While not all interviewees had official mentors, all but two talked about someone who played that role in their career. Some respondents had several mentors over the years while others had one or two people whose advice they sought out repeatedly throughout their careers. The interviewees recognized the importance of the advice they received from their mentors on business issues, personal development and career progression. This is an important finding. As Rosser (2005) has pointed out, while mentoring is a long established human resources development tool, “...few studies have explored mentoring as an educational tool for developing leaders/CEOs..."

The respondents who worked with their mentors (and whose mentors were on organizational leadership teams) often talked about being engaged in various discussions or brought into meetings which they would not have participated in otherwise. This allowed them to watch their mentors "in 
action" and to see how they "approached problems... and issues". For many executives, their mentors had a strong impact on their career path, pushing them outside their comfort zone, encouraging them to move to other positions and giving them confidence that they have the necessary skills to succeed.

\section{OTHER IMPORTANT FINDINGS}

Throughout the interviews we identified additional important factors that emerged as recurring themes.

\section{The Changing Role of IT}

Many interviewees believed that the role of IT has changed and will continue to change. IT is a relatively new field and one of the executives described their early role as "first generation IT", while another said: "when I got into the field, there was no field". In the early days all IT professionals "came from somewhere else" whereas today the IT career paths are more specialized, often starting with IT-focused degrees and certificates.

Some respondents felt that because the field was new, people had a chance to progress through their careers more quickly than would be possible in other areas. As IT grew, a more structured technology career path emerged. Today, the path is changing again, evolving into what one respondent called a "dual stream within IT". The traditional roles focused heavily on technology are complimented by more business-focused roles, such as business analysts ${ }^{6}$. From the leadership standpoint, IT executives "...evolved significantly from just being the... IT guy or the IT leader to having responsibilities around innovation, creation, productivity, operational efficiency..." and "enabling the organization with technology."

As the IT field grows, it continues to change. From the technology standpoint, IT departments have become an essential part of virtually all organizations. While some companies still view IT as a utility, it is increasingly becoming an integral part of the business. From an organizational perspective, another change has been taking place - “...IT was a silo for a very long time and... those lines have blurred in the last 10 years..." More and more organizations break the previously predominant structure where IT and the business were clearly separated, both organizationally and culturally. Today, with the growing amount of customer-facing technologies, IT is ceasing to be just a support function and is increasingly becoming an integral part of the business.

This change in the IT field is not just a thing of the past; it continues and should be recognized by today's CIOs. New technology and new delivery channels continue to bring more change. One of the interviewees explained the impact that the new technologies, such as cloud computing, have had on their organization and their role: “...if you were to look at my company I have no servers, I have no data center, I have no email systems, I have no ERP systems... So the traditional IT CIO role just doesn't exist and yet I'm doing all of the things that I did..." within the traditional IT model.

\section{Trust and Credibility}

The ability to build trust and credibility was another factor which interviewees often talked about, stressing its importance in their career progression and in their relationships with both the subordinates and the peers. It is important to keep in mind that “...you're not going to please everyone all the time, but there needs to be a level of trust that you're doing the right thing from the perspective of the overall company..."

The ability to build trust is dependent on several of the previously described factors. Firstly, a CIO has to be able to deliver on promises and provide proven results in order to gain trust in their abilities to execute. Additionally, this should be supported by good interpersonal skills and executive level communication skills. Overall, these elements will build a level of trust that will help the CIO be fully accepted as one of the C-level executives and overcome the stereotype of technology-focused IT specialist with limited understanding of business. 


\section{Lateral Moves}

The interviewees identified lateral movements as a way to gain valuable business experience. When searching for development and career opportunities many IT professionals look for positions higher up on the functional diagram but in order to go up it is often better to first step sideways. While "there is no standard playbook" that describes the best career path for IT leaders and CIOs, the respondents generally agreed that experience in various roles outside of IT brings an invaluable addition to the technical skills. In the words of one interviewee, “...you have to be willing to step backward to move forward..." Many participants urged CIOs to get out of the IT field and take advantage of opportunities outside their area, before considering a move to a higher role.

\section{Emotional Intelligence}

Emotional intelligence combines a number of soft skills that complement the CIOs technical knowledge to make them great leaders. It is focused both internally (on the CIOs ability to manage their emotions and be self-motivated) and externally (on their ability to be empathetic to other people's needs, be able to build interpersonal relations, and communicate effectively). Several participants pointed out that IT professionals are more likely to lack skills in this area. One explained that “...it's easier to deal with computers than people. Because computers don't get mad at you and they don't have emotions that you would have to deal with and all these complexities that humans have. They are very logical and a program either complies or it doesn't. There's reasons why it doesn't comply and it's always consistent..."

These are not skills that people have to be born with. Several interviewees admitted that this did not come naturally to them; one participant talked specifically about being introverted and having to work harder on these skills. What emerged throughout our conversations with successful CIOs was not their natural inclination towards certain behavior (such as being more extroverted) but the awareness and willingness to develop those skills as necessary.

The Canadian CEOs who took part in the first phase of the study also permitted us to assess their emotional intelligence (EQ) by completing the Leadership Dimensions Questionnaire (LDQ) - a well-established psychometric tool. All participants exhibited emotional intelligence at a level considerable higher than that of the wider population of managers. This demonstrates that high levels of leadership competence are required to advance to the CEO position and to be successful in that role.

As Korn/Ferry International has found in examining the career progression of several thousand successful executives, a journey up the corporate ranks requires a change in leadership style. Successful executives were able to transition from a task-focused approach to a more flexible, participative leadership style (much more so than those who have not been as successful). In other words, senior executives must take steps to prepare for and approach the changes that are required as they expand their responsibilities and progress in their careers.

\section{IMPLICATIONS FOR TODAY'S IT LEADERS}

The results of our analysis show that the CEO office door is open to CIOs, but that CIOs have to gain the right to enter that door. Although individuals can plan their careers to the top, it is what they do along the way that really matters. Before reaching out for the CEO position, they have to prove that they have the experience and the skills that make them the right candidate.

The goal of this research is not to describe how to be a good CEO, but rather to provide help on getting there. The journey to the top starts with being an outstanding CIO and gaining the credibility, experience and skills that are necessary to make it to the CEO level. In the next section we list the key areas and specific action items that CIOs should consider in the context of their career planning and, most importantly, in the context of delivering excellent results as CIOs. Indeed, even if an individual has no intentions to become a CEO, the following steps still apply and will help them become an exceptional CIO. The key elements that influence career progression of CIOs are shown in Figure 3. 
Based on the research findings, the first step in successful CIO career progression is to build credibility through performance by providing results, demonstrating a business focus (supported by business knowledge), and showcasing the ability to be a business leader. This approach allowed the interviewees to overcome the negative IT stereotype and gain a seat at the executive table. Being accepted as one of the C-level executives led to more opportunities, as the CIO role was more likely to report directly to the $\mathrm{CEO}$ and as the $\mathrm{CIO}$ became more visible to the board. As shown by the interviewees' career paths, this increased visibility, combined with credibility, tends to open many new doors for CIOs

Secondly, it is important that CIOs orchestrate their career moves and take actions that will prepare them for the top executive role. These actions have to aim at developing the necessary skills, gaining relevant experience and being able to showcase readiness for the top role. At the same time, successful CIOs are able to take advantage of opportunities that present themselves along the way and which support career progression. These elements are described in further detail below.

\section{Build Credibility}

As previously mentioned, building credibility is based on combining business knowledge with relevant skills and leadership traits.

\section{Build Credibility Through Knowledge}

In order to gain credibility through knowledge CIOs need to prove that they are not only good at CIO basics, but also that they deliver technology with the full understanding of its business context. In order to acquire the increased business focus, CIOs must gain relevant work experience outside of IT and take on firm-wide responsibilities. When it comes to understanding and knowing the business (and its customers), only first-hand experience can truly prepare CIOs for the requirements on higher executive positions. At the same time, it serves both as a way to demonstrate an interest in professional self-development as well as a means to validate business skills.

\section{Build Credibility Through Skills Development}

Being able to deliver results in only one part of the equation. To be truly successful, CIOs must also develop a set of interpersonal skills that will allow them to be great communicators, build strong relationships and motivate their team. These traits become more important with each step up the corporate ladder and are a key requirement for the CEO position.

Figure 3. Elements influencing $\mathrm{ClO}$ career progression

\section{CIO TO CEO}

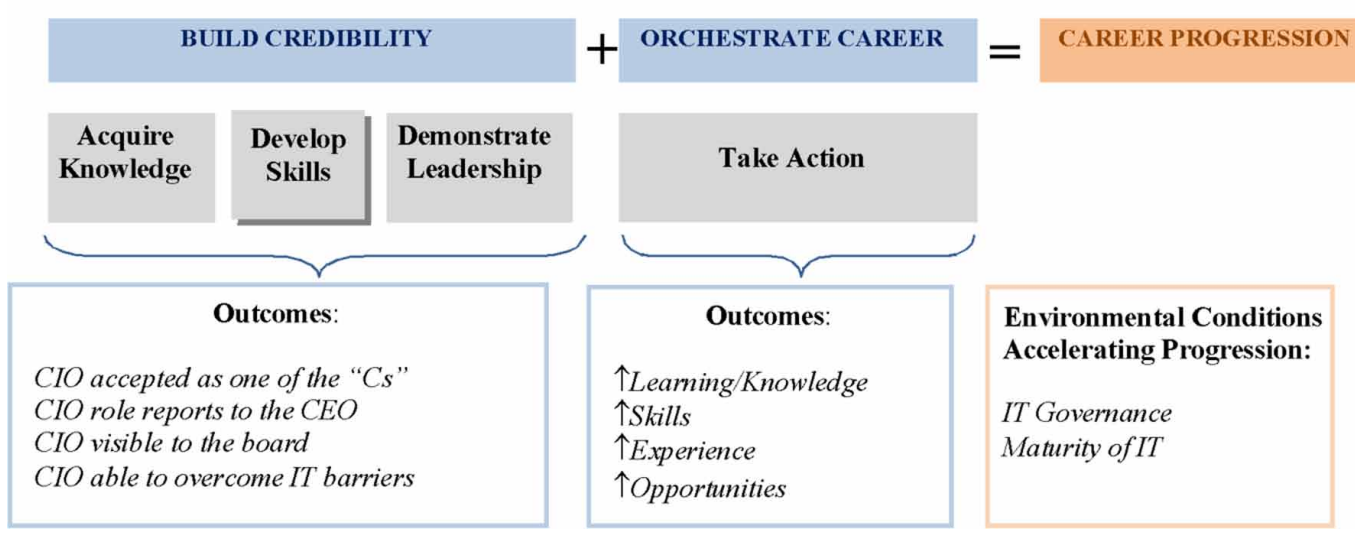




\section{Build Credibility Through Leadership}

Finally, successful CIOs have to exhibit the ability to introduce change in their organizations and be able to motivate and develop their teams. Not only can they identify improvement opportunities and act on them, but they also know how to effectively communicate the value that they bring to the business and the IT organization. At the same time, they recognize the importance of motivating their teams and aligning their organizations to common goals. Even the best-designed plans cannot be executed successfully without a team buy-in or at the very least understanding as to the goals and rationale. Successful CIOs are open about their strategies and know how to address important issues with various affected stakeholders.

\section{Orchestrate Your Career}

In order to advance beyond their current role, CIOs have to actively take control of their career progression. Successful CIOs are not afraid of taking up challenging high-visibility projects and reaching out beyond their comfort zone. For many CIOs, the importance of building professional networks is invaluable in their ability to make it to the top. While opportunities for CIOs exist, they typically present themselves as a result of the CIO's "brand" recognition among the executive and among their peers. While not all CIOs who progressed in their career actively searched for advancement opportunities, all were able to demonstrate that they were ready to step up to a higher role.

\section{AN ACTION PLAN FOR CIO CAREER PROGRESSION}

Based on the identified research implications for $\mathrm{CIO}$ career progression, this section presents concrete steps that CIOs can take to build credibility through knowledge, skills and leadership, as well as to orchestrate their career advancement.

Although not all of the respondents actively planned their career progression, they all took actions to become outstanding CIOs (which led to advancement opportunities). The following discussion will be helpful to you whether you aspire to become a CEO or simply want to increase your impact in your current position. Key to successful advancement is building credibility. Figure 4 shows how this can be done.

All of the interviewees took actions that helped them shape their careers, even though career advancement wasn't necessarily their main motivator. Specifically, they actively sought ways to gain

Figure 4. Building credibility

\section{BUILD CREDIBILITY}

\begin{tabular}{|l|}
\hline Acquire Knowledge \\
\hline Increase your Business \\
Knowledge: \\
- Understand the business \\
- Gain the needed business \\
experience \\
- Improve your knowledge \\
- Get involved in a wide range \\
of corporate activities \\
\hline
\end{tabular}

\begin{tabular}{|l|}
\hline Develop Skills \\
\hline Develop Personal Skills: \\
- Complete self-assessment \\
and reflection \\
- Assess and work to improve \\
your emotional intelligence \\
- Build a reputation for \\
developing staff and building \\
successful teams \\
\hline
\end{tabular}

\begin{tabular}{|l|}
\hline Impact Leadership \\
\hline $\begin{array}{l}\text { Demonstrate Business } \\
\text { Leadership }\end{array}$ \\
- Be a change leader \\
- Improve IT governance \\
\\
\hline
\end{tabular}




\section{ORCHESTRATE YOUR CAREER}
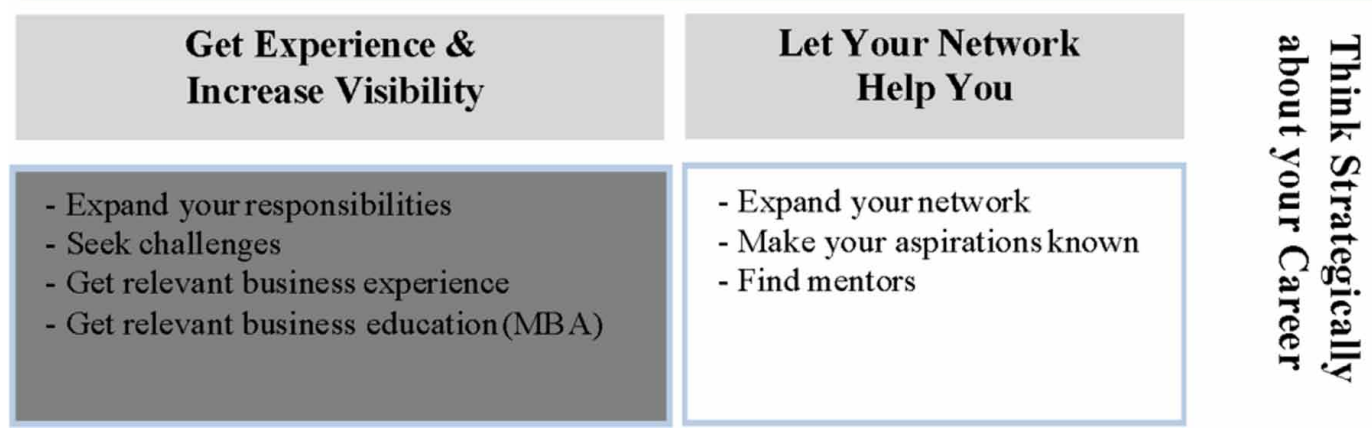

more experience, they built relationships with peers and mentors, and (where they did seek to move into hirer positions), and they made their aspirations known and approached them strategically. Figure 5 shows how this might be done.

\section{CONCLUSION}

This study has demonstrated conclusively that successful CIOs are able to move beyond their specialist leadership role to the top positions within organizations. There was a surprisingly high degree of commonality in the career development of all the individuals interviewed. They were successful at IT leadership and they demonstrated increasing understanding of the business environment as well as an ability to take on broader responsibilities beyond IT.

Most were respected IT leaders who demonstrated credibility to their peers and superiors. They were willing to take on responsibilities beyond their own area (sometimes through lateral moves), they had executive level communication skills and were able to build relationships as well as developing and motivating their subordinates. In gaining wider business knowledge they got to know their businesses customers and needs, and then were able to assist their peers in meeting these needs.

Their success can be replicated by others aspiring to advance their career, through a combination of learning activities and actual behavior. 


\section{REFERENCES}

Bossert, O., Harrysson, M. \& Roberts, R. (2015). Organizing for digital acceleration: Making a two-speed IT operating model work. McKinsey \& Company. Retrieved from www.mckinsey.com/industries/high-tech/outinsights

Chatham, R. (2005). Getting to be CEO via a Career in IT. London: CSC's Research \& Advisory Services.

Dawson, G. S., Ho, M. W., \& Kauffman, R. J. (2015). How are C-suite executives different? A comparative empirical study of the survival of American chief information officers. Decision Support Systems, 74, 88-101. doi:10.1016/j.dss.2015.03.005

Egon Zehnder International. (2007). Future-State CIO: The Next Step for IT-Business Leadership. CIO Executive Council.

Eisenhardt, K. M. (1989). Building theories from case study research. Academy of Management Review, 14(4), 532-550. doi:10.5465/amr.1989.4308385

Feeny, G., Edwards, B. R., \& Simpson, K. M. (1992, December). Understanding the CEO/CIO Relationship. Management Information Systems Quarterly, 16(4), 435-448. doi:10.2307/249730

Frydman, C. (2007). Rising Through the Ranks. The Evolution of the Market for Corporate Executives, 19362003. MIT Sloan Working Paper.

Gottschalk, P. (Ed.). (2006). CIO and Corporate Strategic Management: Changing Role of CIO to CEO: Changing Role of CIO to CEO. Hershey, PA: IGI Global.

Goudreau, J. (2012, October 29). Do You Have 'Executive Presence'? Forbes Magazine.

Grant, K., \& Hutson, M. (2009). How do CIOs Become CEOs? Barriers and Success Factors. In 3rd European Conference on Information Management and Evaluation, Gothenburg. Sweden, September 17.

Heller, M. (2016). Be the Business: CIOs in the New Era of IT. Routledge.

Hunter, G. (2010). The chief information officer: A review of the role. Journal of Information, Information Technology, and Organizations, 5(1), 125-143. doi:10.28945/1328

Hütter, A., \& Riedl, R. (2017). Chief Information Officer Role Effectiveness: Literature Review and Implications for Research and Practice. In Chief Information Officer Role Effectiveness (pp. 1-30). Springer International Publishing. doi:10.1007/978-3-319-54753-4

International Data Corporation (IDC). (2015). The Changing Role of IT Leadership: CIO Perspectives for 2016. International Data Corporation (IDC). (2016). Worldwide Digital Transformation 2017 Predictions.

Kohli, R., \& Johnson, S. (2011). Digital Transformation in Latecomer Industries: CIO and CEO Lessons from Encana Oil and Gas (USA) Inc. MIS Quarterly Executive, 10(4), 141-156.

Leidner, D., \& Chen, D. (2008). CIO Leadership Profiles: Implications of Matching CIO Authority and Leadership Capability on IT Impact. MIS Quarterly Executive, 7(2), 57-69.

May, T. A. (2007, January 22). Why Don't More CIO’s Become CEO? Computerworld.

Milovich, M. (2015). Keeping Up with IT Strategy in a World of Constant Business Change. MIS Quarterly Executive, 14(3), 125-135.

Myers, M. D., \& Newman, M. (2007). The qualitative interview in IS research: Examining the craft. Information and Organization, 17(1), 2-26. doi:10.1016/j.infoandorg.2006.11.001

Peppard, J. (2010). Unlocking the performance of the chief information officer (CIO). California Management Review, 52(4), 73-99. doi:10.1525/cmr.2010.52.4.73

Peppard, J., Edwards, C., \& Lambert, R. (2011). Clarifying the ambiguous role of the CIO. MIS Quarterly Executive, 10(1), 31-44.

Peters, T., \& Waterman, B. (1982). In Search of Excellence. New York: Warner Books, Inc. 
Remenyi, D., Grant, K. A., \& Panther, S. (2005). The Chameleon: A Metaphor for the Chief Information Officer. Journal of General Management, 30(3).

Rosser, M. H. (2005). Leadership and Mentoring: CEO Perspectives. In Annual Conference of the Association of Leadership Education, Wilmington, NC, July 11-14.

Schnatterly, K., \& Johnson, S. G. (2008). Competing to be CEO in high-tech firms: Insider, board member, or outsider candidates. The Journal of High Technology Management Research, 18(2), 132-142. doi:10.1016/j. hitech.2007.12.005

Synnott, W. R. (1987). The Information Weapon: Winning Customers and Market with Technology. New York: John Wiley \& Sons.

Synnott, W. R., \& Gruber, W. H. (1981). Information Resource Management: Opportunities and Strategies for the 1980s. New York: John Wiley \& Sons.

Synnott, W. R., \& Gruber, W. H. (1981). Information Resource Management: Opportunities and Strategies for the 1980s. New York: John Wiley \& Sons.

Weill, P., \& Woerner, S. L. (2013). The Future of the CIO in a Digital Economy. MIS Quarterly Executive, 12(2), 65-75.

Westerman, G., \& Weill, P. (2004). What makes an effective CIO? The perspective of non-IT executives. Center for Information Systems Research, Sloan School of Management, Massachusetts Institute of Technology.

Yin, R. K. (2009). Case study research: Design and Methods. Thousand Oaks: SAGE publications.

\section{ENDNOTES}

Bill Synnott is widely credited for the creation of the term (Synnott \& Gruber, 1981; Synnott, 1987)

The development of this model is reported in (Grant \& Hutson, 2009)

See IDC Worldwide Digital Transformation 2017 Predictions, September 2016, IDC \#US40526216; and

IDC The Changing Role of IT Leadership: CIO Perspectives for 2016, December 2015, IDC \#US40662915

4 For an in-depth example of the CIO role in business transformation using technology, see (Kohli \& Johnson, 2011)

5 Further elaboration of this concept is provided by (Leidner \& Chen, 2008)

6 This is sometimes referred to as "two-speed IT", as described by (Bossert, Harrysson, \& Roberts, 2015)

Ron Babin is a Professor in the Ted Rogers School of IT Management at Ryerson University. Prior to joining Ryerson, he enjoyed over 25 years of professional IT experience, concluding as a strategy partner at Accenture. 